\title{
A Gramática Visual e o livro didático
}

\section{Cristina Helena Evelyn Tinoco Teixeira PUC-Rio}

\begin{abstract}
Este trabalho examina o uso de imagens em um livro didático de ensino de inglês como língua estrangeira, analisando as páginas compostas por texto e imagem em três unidades deste livro. A análise se baseia nos três princípios de composição de textos multimodais: valor informativo, saliência e, enquadramento. $\mathrm{O}$ estudo questionou se as diferentes modalidades semióticas (imagens, gráficos e texto) e seus significados individuais estavam interagindo entre si e influenciando-se mutuamente em um texto integrado nas páginas analisadas. O estudo revelou que, apesar do livro analisado ser claramente um livro Multimodal, existe, no entanto, uma tendência da imagem estar presente para 'servir' o texto verbal.
\end{abstract}

PALAVRAS-CHAVE: Multimodalidade, texto, imagem, texto integrado

\section{INTRODUÇÃO}

A grande quantidade de imagens que hoje aparecem nas diferentes práticas de escrita colocou a linguagem visual em evidência. Textos que apresentam duas ou mais modalidades semióticas em sua composição tomaram o lugar das tradicionais práticas da escrita, provocando efeitos nos formatos e nas características destes textos, resultando no que foi denominado de Multimodalidade. A noção de texto passa a ultrapassar os limites do código lingüístico. Quando nos referimos a textos hoje em dia, nos referimos à noção de conjunto - texto e imagem - construídos pela intenção de quem produz estes textos em nos fazer crer na sua visão e no seu recorte do universo. Cito aqui a proposta teórica de Kress e van Leeuwen (1996) para uma Gramática Visual que discute parâmetros de observação para a análise de imagens que, juntamente com a modalidade escrita, compõem o sentido do texto. O que é expresso na linguagem verbal pela escolha de palavras e estruturas é, na imagem, expresso pela escolha de cores e a composição, entre outros elementos. A imagem, que comunica mensagens com força e facilmente, é construída de maneira intencional e penetra na cognição social e, muitas 
vezes, modifica ideologias e paradigmas. Isto dá ao texto Multimodal mais poder que um texto apenas verbal e por esse motivo exige uma leitura de caráter crítico.

A Gramática Visual de Kress e van Leeuwen (1996) analisa as maneiras como as imagens representam as relações entre as pessoas, os lugares e os objetos que nelas estão retratados. Toda imagem contém uma série de representações e relações de interação. $\mathrm{Na}$ análise das representações, segundo esse estudo, elas podem ser de negociação ou de não-negociação, estando ou não interagindo entre si. O estudo analisa também as relações de interação entre o que está retratado na imagem e o observador que olha a imagem. Uma terceira análise estuda o posicionamento destes elementos dentro da imagem como um todo, e também o quanto cada elemento está enfatizado dentro da composição da imagem. Esta composição relaciona, então, significados representacionais e interacionais a três sistemas inter-relacionados denominados: valor informativo (que dá diferentes valores a cada coisa retratada conforme a região onde está posicionada na imagem), saliência (que dá proeminência ao que está retratado segundo tamanho, cor e outros elementos) e enquadramento (que une ou separa elementos retratados através de linhas de divisão ou mesmo molduras).

De acordo com Kress e van Leeuwen (1996), estes três princípios também regem os textos multimodais, que devem ser analisados e tratados de uma forma integrada, evidenciando a interação entre as partes (texto e imagem), a composição de um todo. Ou seja, o texto multimodal revela um código mais abrangente com regras e significados que reunem diferentes códigos semióticos. A integração desses códigos serve para produzir textos coerentes e ordenados a partir da colocação das partes significativas neste todo, o que é a atribuição da função composicional.

O objetivo de meu trabalho é analisar os três princípios da composição sugeridos por Kress e van Leeuwen (1996) nas páginas (unidades) de um livro-texto para o ensino de língua estrangeira (LE). Baseei meu estudo na procura de respostas a dois questionamentos sobre as páginas (unidades) analisadas: a) Os elementos dispostos nos layouts das unidades estão construindo significados conforme os princípios citados? b) Esses textos e imagens estão interagindo e afetando um ao outro, formando um texto integrado na composição de um todo, como ocorre nos textos que apresentam multimodalidade?

\section{MÉTODO}


O livro Green Flash 2 (livro do aluno) foi examinado principalmente por ser, além de um livro que apresenta textos multimodais em todas as suas unidades, um livro de edição atual (2004) - posterior à teoria analisada e à profusão da noção de multimodalidade.

O livro Green Flash 2 (livro do aluno) é o segundo livro de uma série de quatro livros da editora Learning Factory, que gentilmente deu o seu apoio ao projeto que resultou no presente trabalho. Cada livro da série faz parte de um pacote composto pelo livro do aluno, o livro do professor, dois CDs de textos orais e músicas (um para sala de aula e outro para casa) e atividades de multimídia para serem feitas em aula (apenas o livro do aluno participa desta análise). Três unidades do livro foram escolhidas ao acaso (ver Anexos 1, 2, 3). As unidades são totalmente independentes entre si e compostas por duas páginas inteiras.

Na minha análise, considerei como imagem toda e qualquer representação visual seja na forma de ilustração, fotografia ou representação de gêneros textuais como $e$ mails, cartas, bilhetes, propaganda, convites impressos, calendários, agendas que apresentam o texto escrito em sua composição (e que sem ele não seriam percebidos como o gênero que estão representando).

Serão verificados os três princípios da composição sugeridos por Kress e van Leeuwen (1996) na análise. Na teoria desses autores, os princípios de valor informativo, saliência e enquadramento podem ser aplicados ao layout, no caso, das páginas do livro Green Flash 2, onde cada página dupla compõe uma unidade que é independente - uma unidade semiótica. 


\section{RESULTADOS}

Nesta parte do trabalho, analiso as diferentes imagens e sua composição nas páginas selecionadas do livro em estudo. Procurarei mostrar os significados das imagens e da sua composição nas páginas e traçar relações com a finalidade pedagógica das atividades nas unidades em estudo.

A Figura 1 mostra a terceira unidade do livro (Unidade A3, páginas 10 e 11). Sua composição ilustra claramente uma estruturação horizontal, e me leva a discutir o primeiro princípio de composição sugerido por Kress e van Leeuwen (1996), o princípio do Valor Informativo esquerda/direita e a noção de dado e novo nesta unidade semiótica.

Figura 1 - Book Green Flash 2, 2004 : Análise do valor informativo (dado e novo)
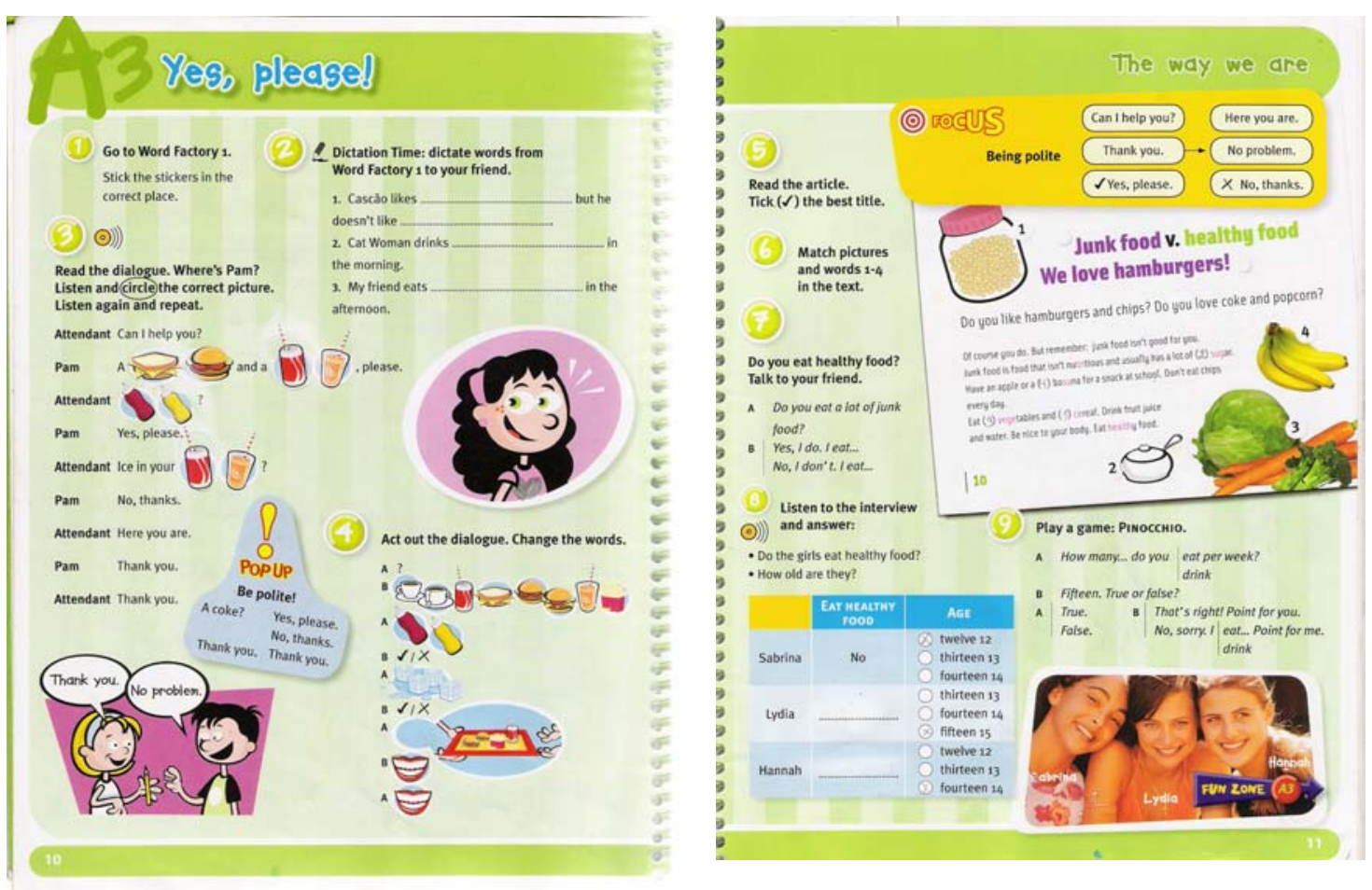

Vejo o lado direito da página dominado por imagens fortes: (1) a representação do que parece ser um artigo (de uma revista) sobre hábitos alimentares (comida saudável ou não) ocupando um bom espaço da área, (2) uma fotografia de três adolescentes com o olhar de demanda acompanhada por um gráfico sobre elas, e (3) o que o livro chama de "Focus" (uma caixa laranja com informações normalmente lingüísticas que aparece em todas as unidades do livro desta forma bastante saliente). Os 
três representam a informação importante a que os alunos (leitores) devem prestar atenção - a informação que é polêmica, contestável - a informação nova da unidade semiótica. Já no lado esquerdo, que apresenta o que é dado, conhecido do leitor, as imagens são menores que as do lado direito. A imagem que mais chama a atenção (mais saliente) é a ilustração da personagem do livro de nome Pam (supostamente conhecida pelos alunos desde o livro 1) e que causa uma reação de não-negociação (“oferta"), pois parece olhar para fora da página - para algo que o leitor ignora. Há um texto escrito que se apresenta na forma de diálogo. Este diálogo formado por texto escrito e imagens (escolhidas de acordo com o que os alunos escutam num CD de áudio, outro modo semiótico) é informação $d a d a$, evidente e incontestável, e por isto dá ao leitor uma natural seqüência de olhar da esquerda para a direita da unidade semiótica.

O mesmo princípio de Valor Informativo - dado e novo - pode ser percebido no exemplo da Figura 2 abaixo analisado (Unidade C1, páginas 26 e 27). O lado direito da unidade semiótica apresenta também força muito maior que o lado esquerdo.

Figura 2 - Book Green Flash 2, 2004: Análise do valor informativo (ideal e real)
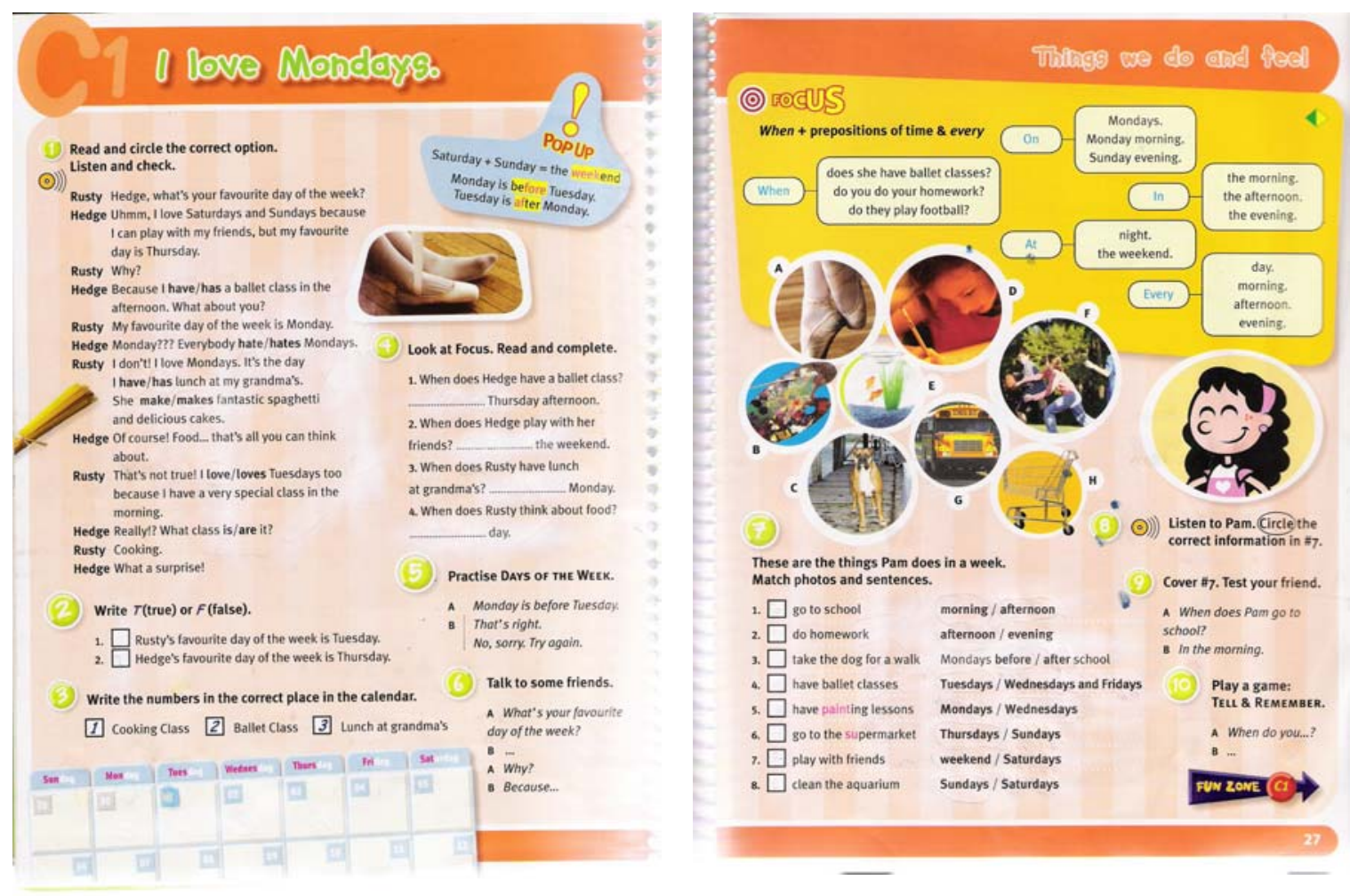
Enquanto o lado esquerdo apresenta principalmente texto escrito, o lado direito, neste caso, está dominado por várias imagens pequenas e uma enorme caixa "Focus" que se localizam na parte superior deste lado.

Vale comentar que, embora as unidades do livro apresentem uma estruturação horizontal clara, minha análise verificou uma certa unidade em estruturação vertical também, tanto na organização em colunas no lado esquerdo, como se levarmos em consideração a "organização da aula" dentro das páginas do livro.

$\mathrm{Na}$ Figura 2, percebo, tanto na página esquerda quanto na página direita, o movimento de cima para baixo, o que nos termos de Kress e van Leuuwen (1996) se traduz como a relação ideal e real, ou a relação entre o abstrato e o concreto. Mas, no caso dessas páginas em análise, pode-se considerar como ideal tudo que é colocado pelo livro em termos de contextualização (abstrata) do assunto a ser tratado - a forma ideal, correta da informação. Esse material ou é dado no formato de exemplos, ilustração, ou é trabalhado de forma controlada, sem espaço para erros. Real seria, então, a aplicação no caso pelos alunos - do que foi imaculadamente exposto. Nas Figuras 1 e 2, percebese claramente este movimento de cima para baixo. Analisando as páginas da Figura 1 separadamente, do lado esquerdo, por exemplo, os alunos partem do diálogo controlado pelo auxílio do CD de áudio para o exercício número 4 no final da página onde eles estão completamente livres para produzir um diálogo real a partir do exemplo ideal anterior. O lado direito desce do ideal da prática alimentar saudável ditada pelo artigo exposto para o real do hábito das adolescentes retratadas e da produção dos alunos no jogo do exercício de número 9.

Na Figura 2, no lado esquerdo, verifica-se claramente o movimento de cima para baixo, começando com o ideal do diálogo controlado também pelo auxílio do CD de áudio, para o real do diálogo entre os alunos, estimulado no exercício número 6 no final desta página. O topo da página do lado direito apresenta a caixa laranja do "Focus" (que será analisada mais adiante como elemento de peso nas unidades analisadas) retratando, assim, o ideal e o final da página, um diálogo real que deve ser produzido pelos alunos motivados pelos ideais da caixa "Focus".

A caixa "Focus" de cada unidade semiótica no livro Green Flash 2 ilustra de maneira clara mais um dos princípios da composição sugeridos por Kress e van Leeuwen (1996) - o princípio da Saliência. Independente do local aonde esta caixa "Focus" tenha sido colocada nas unidades semióticas sendo analisadas, é fácil perceber que elas têm um grau de importância, evidenciando este princípio da composição. 
As caixas "Focus" são apresentadas em cor diferente e mais forte (laranja) que a cor do fundo das unidades semióticas aonde aparecem. Devido ao efeito de sombra quase sempre presente nas caixas, elas parecem ser "de verdade", como um anexo àquela realidade. Todas elas apresentam o desenho de um alvo ao lado do nome "Focus", como que se quisessem despertar a atenção do olhar do leitor. Todos estes detalhes de saliência criam na caixa de "Focus" uma importância em relação aos outros elementos do conjunto das unidades semióticas.

A Figura 3 ilustra a unidade E2 do livro. Analisando a composição, posso perceber que o dado e o novo apresentam igualdade de saliência. Mas, se analisarmos ideal e real da composição, verificamos que o ideal está mais saliente que o real. $\mathrm{O}$ peso dos elementos na composição nos força a dar mais atenção aos mais salientes, e manipulam nossas escolhas para o que queremos ou não prestar atenção. As Figuras 1, 2 e 3 apresentam um elemento denominado "Pop Up", que traz curiosidades sobre a língua inglesa.

Figura 3 - Book Green Flash 2, 2004: Análise de saliência
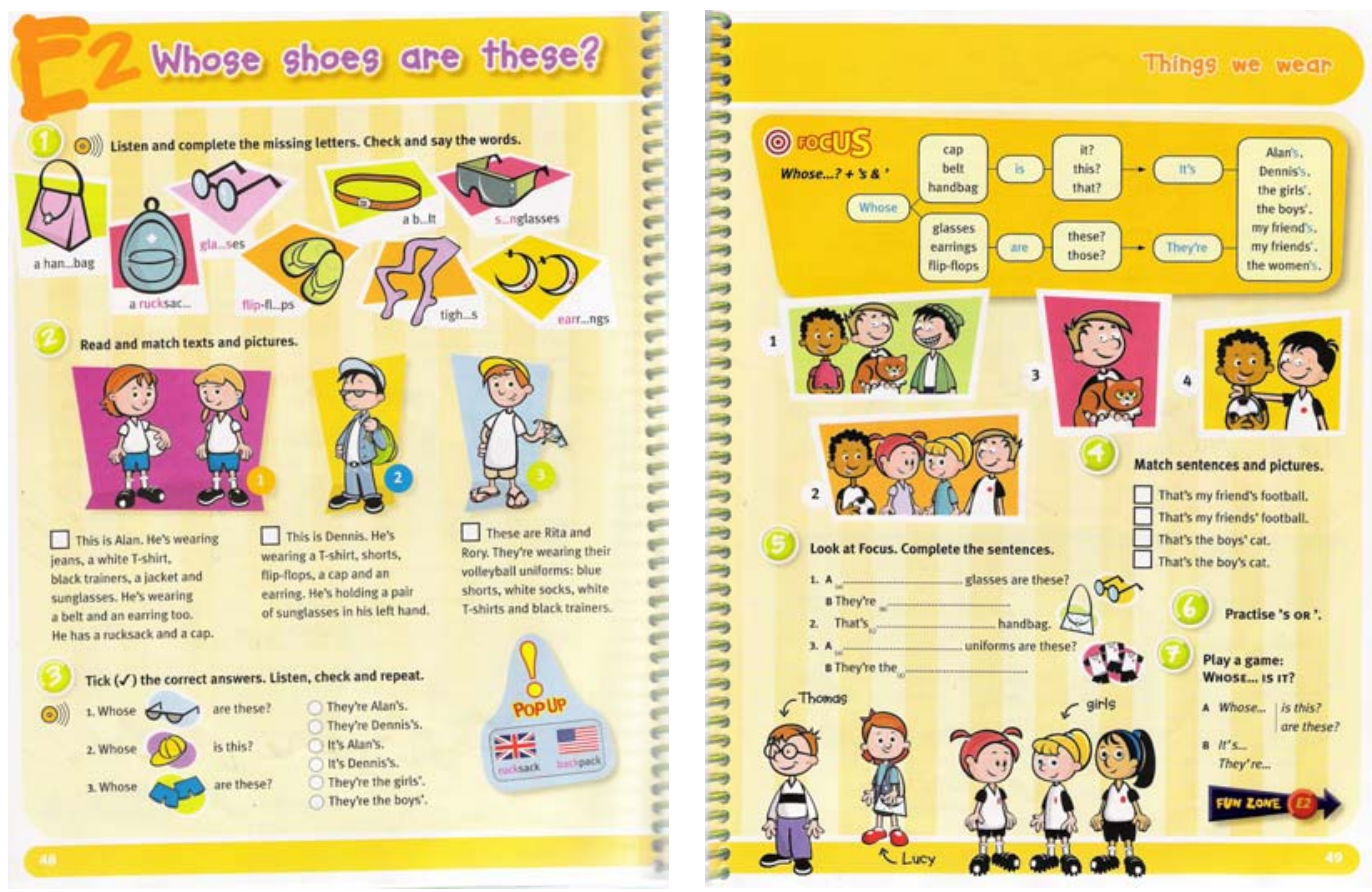

Embora fora do contexto da ordem natural da unidade, os "Pop Ups" nunca passam despercebidos (nem mesmo se não mencionados pela professora). Isto acontece devido ao princípio de Saliência descrito acima. 
O último princípio de composição sugerido por Kress e van Leeuwen (1996), o princípio do Enquadramento, cita que elementos ou grupos de elementos num layout podem estar desconectados ou conectados uns dos outros (discutido também em Unsworth, 2001). Layouts onde os elementos estão completamente desconectados têm enquadramento forte. Layouts onde os elementos são fortemente conectados têm enquadramento fraco. Quanto mais enquadrado o elemento está em si mesmo, mais este elemento está enfatizado como uma informação à parte do todo.

Analisando as unidades selecionadas, vemos que, de um modo geral, as unidades têm muitos elementos fortemente enquadrados e por isso expressam muita desconexão entre as partes. O único recurso de integração entre os elementos é o uso dos números da mesma cor e em ordem crescente que (como vetores) forçam o leitor a uma leitura obedecendo à ordem numérica dos elementos, num movimento contínuo, e nunca em vai e vem ou aleatoriamente como os textos modernos que se intitulam interacionais.

Na Figura 1, com unidade A3, a ilustração da personagem Pam se encontra em um enquadramento forte, isolada de qualquer outro elemento. A imagem do artigo, no lado direito da unidade, foi sobreposta pela caixa do "Focus" que não tem nenhuma relação lingüística, funcional ou de conteúdo com o artigo. A imagem das adolescentes, fortemente enquadrada, e levemente tocada pelo quadro que efetivamente trabalha esta imagem criando relação entre elas, foi parcialmente encoberta por uma seta denominada "Fun Zone" (de muita saliência), que direciona o leitor para uma outra página do livro que já não trabalha nada sobre a imagem.

Na Figura 2, com a unidade C1, a fotografia da sapatilha de balé é meramente uma ilustração de um dos assuntos tratados no diálogo apresentado. Também muito enquadrada, se isola na página, sem ter participação efetiva na produção do sentido, característica almejada pelo texto multimodal. As muitas imagens que sangram a caixa de "Focus" do lado direito da unidade também são, como a sapatilha, meras ilustrações de atividades de rotina diária e não participam na elaboração do sentido almejado pela caixa "Focus", que seria a manifestação destas práticas no tempo.

A Figura 3, com a unidade E2, apresenta uma quantidade enorme de imagens. Apesar de a maioria destas imagens estar muito enquadrada e ter sido usada apenas como ilustração de vocabulário do texto verbal, algumas delas conseguem ter uma participação mais integrada a outros elementos do texto. Cito os exercícios 2, 3 e 5, onde as imagens são essenciais para a produção de sentido (diferente sentidos nos exercícios). As imagens que sangram a caixa do "Focus" não têm finalidade integrada 
ao que a caixa está trabalhando, mas ficam isoladas do texto com o qual deveriam ter integração (exercício 4).

\section{DISCUSSÃO E CONCLUSÃO}

Neste estudo, procurei analisar as páginas de três unidades de um livro-texto de ensino de Inglês como Língua Estrangeira aplicando o princípio de composição sugerido por Kress e van Leeuwen (1996) para tentar observar se os elementos dispostos nos layouts das unidades estão construindo significados conforme os princípios dos autores. Minha análise sugere que os três princípios de representação e relações de interação foram confirmados nas práticas das unidades em questão:

- O princípio do Valor Informativo esquerda/direita e a noção de dado e novo foi claramente descrito nos resultados; assim como o Valor Informativo de movimento de cima para baixo, ideal e real também foi possível de ser identificado e exemplificado.

- O princípio da Saliência está facilmente reconhecido nas unidades analisadas. O excesso de enquadramento, cores e contrastes, principalmente das imagens das unidades, cria saliência nestes elementos que passam, visualmente, a ter peso forte na composição como um todo. Existe, no entanto, uma perda no excesso do uso deste princípio, pois o leitor tende a desistir de entender qual é o elemento que efetivamente tem a importância naquele material de leitura, não percebe por que caminho deve seguir sua leitura, e acaba por "olhar" muito e "ver" pouco.

- O princípio de Enquadramento foi analisado nas unidades em questão chegando ao resultado de um conflito de características deste princípio dentro destas unidades. Muito embora as unidades apresentem seus elementos organizados com números em ordem crescente, que de uma forma clara faz a ligação de um elemento com o outro (funcionando como vetores), o excesso de enquadramento das imagens de uma forma isolada dá a impressão de desconexão entre os elementos destas unidades semióticas. Com raras exceções, as imagens não estão diretamente ligadas aos textos verbais com a intenção de construir significado. 
O livro-texto Green Flash 2 é, definitivamente, um livro multimodal pois apresenta uma soma das linguagens verbal e visual, para não citar as linguagens sonora e de movimento nos CDs de áudio e programas de computador que acompanham a série. Apesar de o livro apresentar a modalidade visual de forma integrada, colaborando na configuração textual, existe, no entanto, uma tendência, do visual estar presente para "servir" o texto verbal, dando apoio de vocabulário, ou apenas ilustrando o livro para fins estéticos. O conceito de multimodalidade prevê o uso dos diferentes modos semióticos para a função a qual eles melhor servem. Todos eles prestam um serviço específico e às vezes insubstituível na construção de significado.

\section{REFERÊNCIAS:}

Kress, G. \& van Leeuwen, T. (1996). Reading images: The grammar of visual design. London: Routledge.

Unsworth, L. (2001). Teaching multiliteracies across the curriculum: Changing contexts of text and image in classroom practice. Maidenhead: Open University Press. 


\section{Anexo 1}

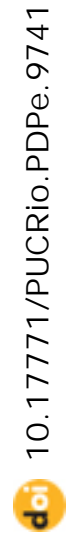
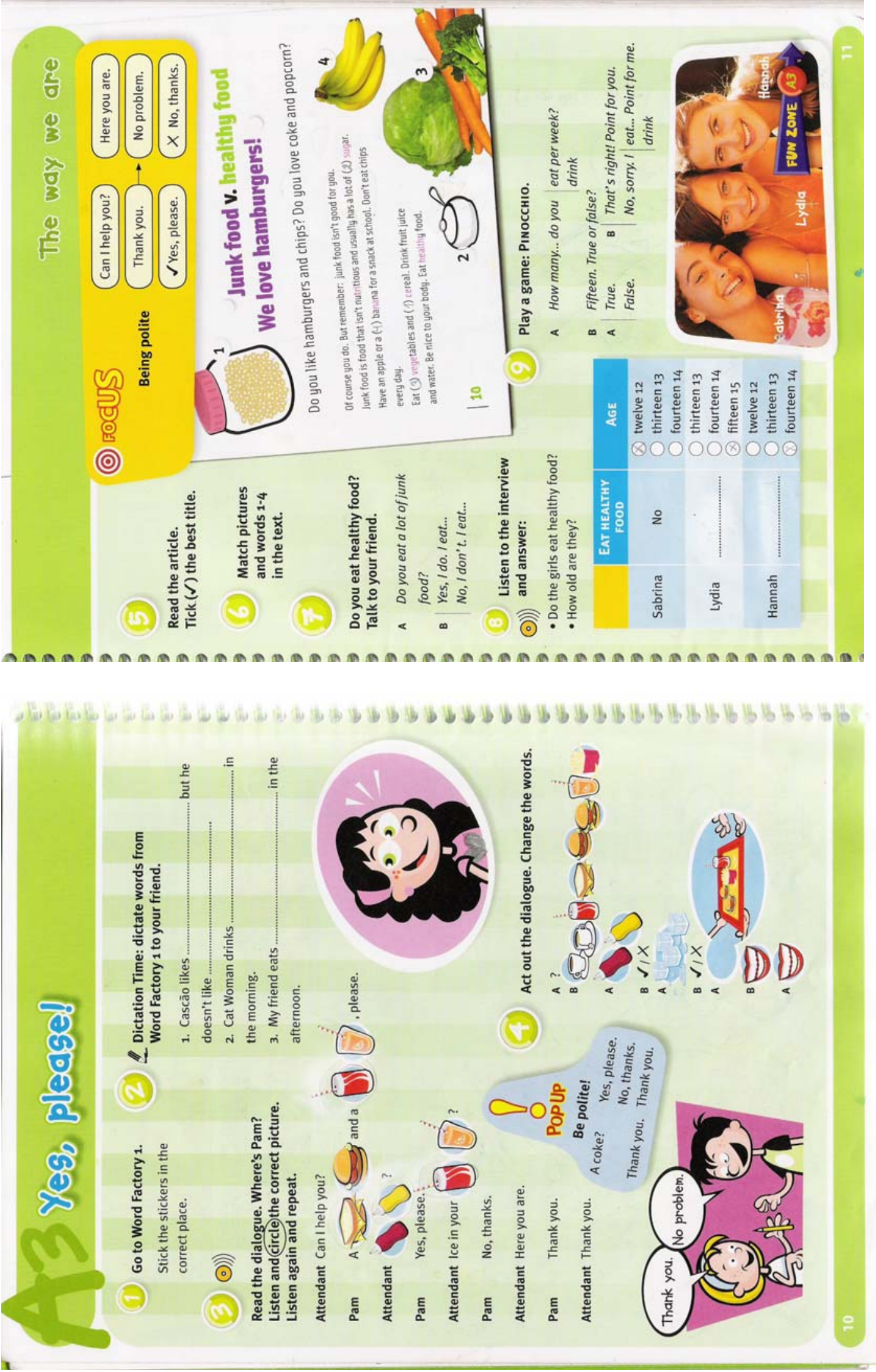


\section{Anexo 2}

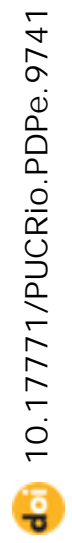

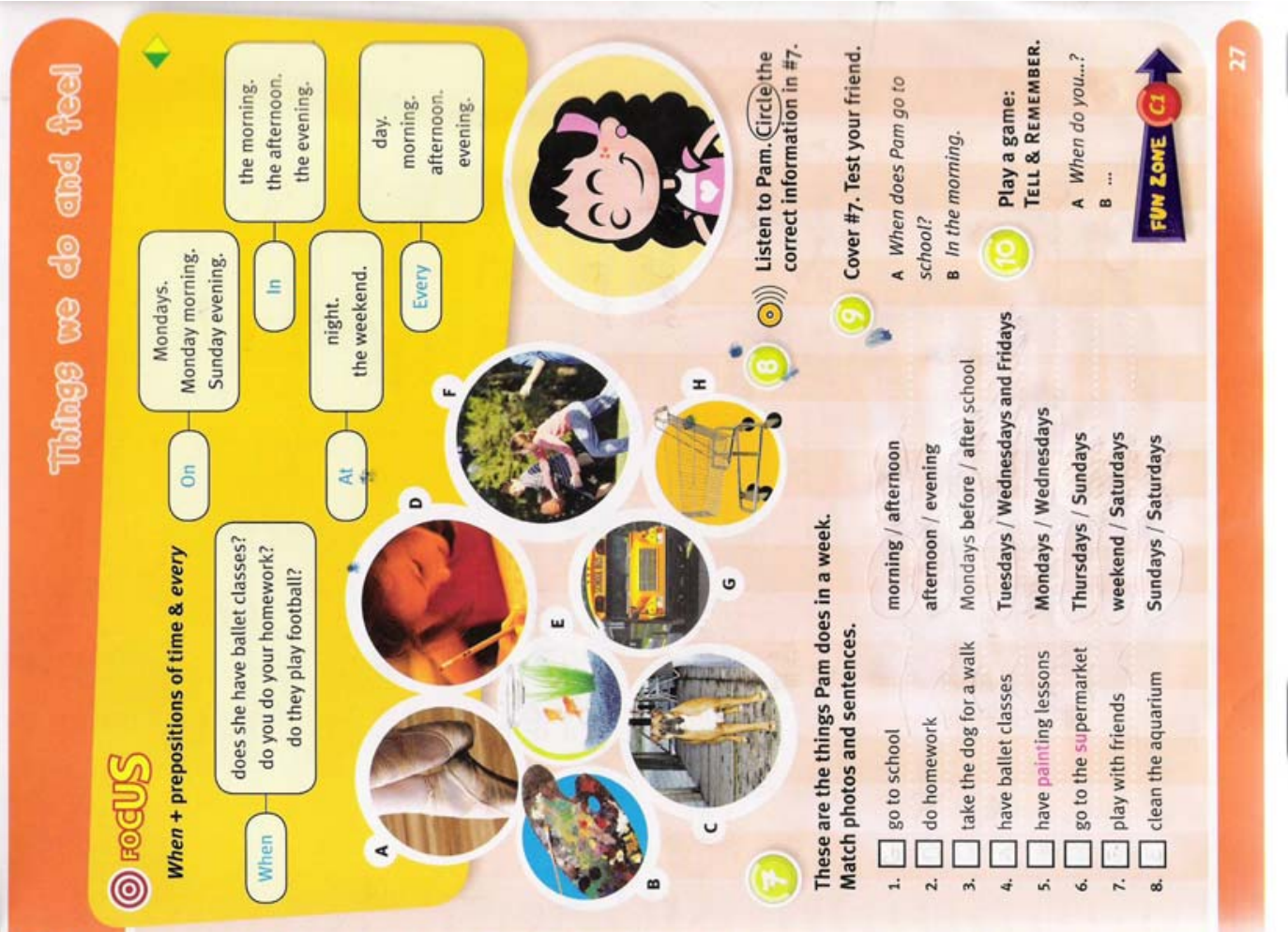

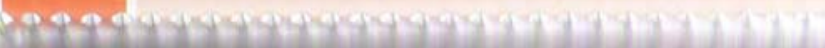

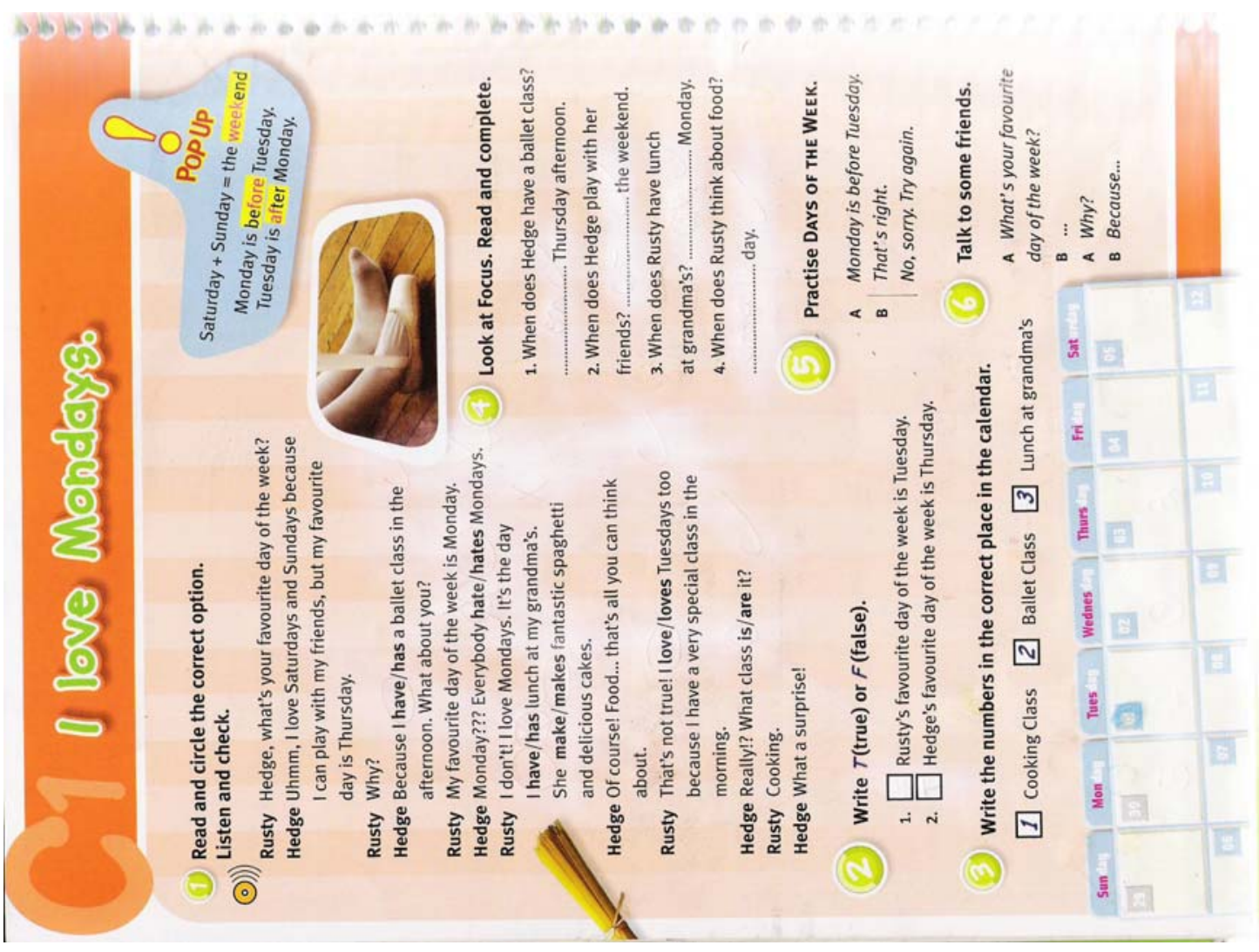




\section{Anexo 3}

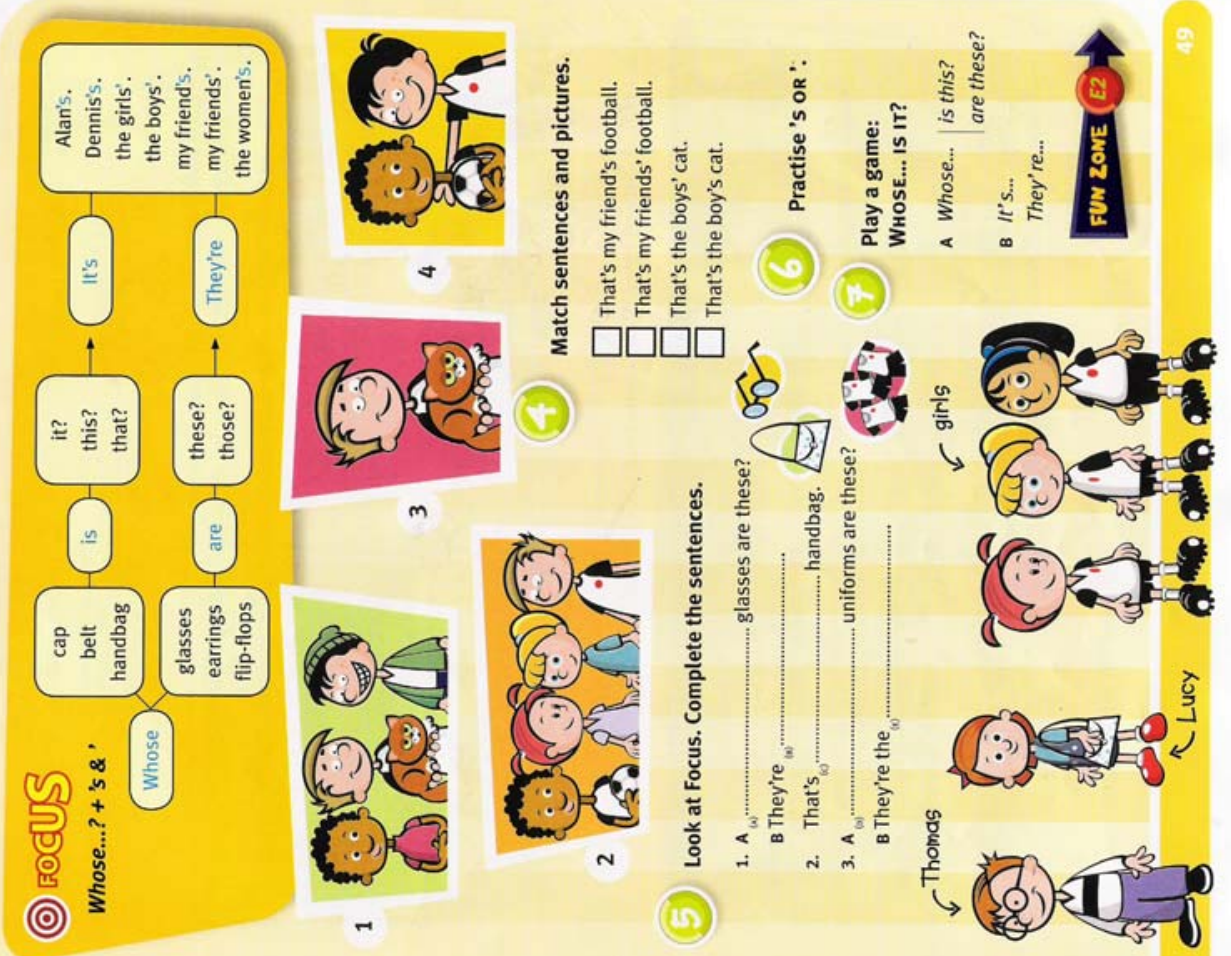

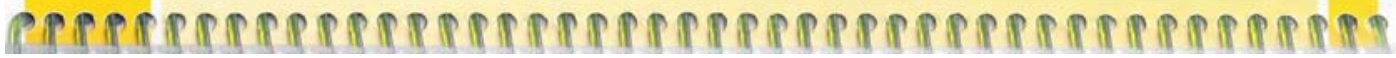

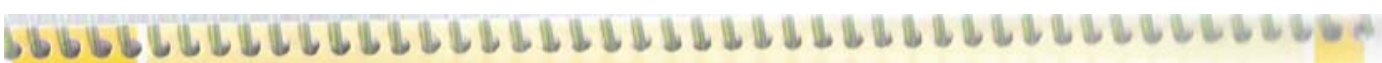

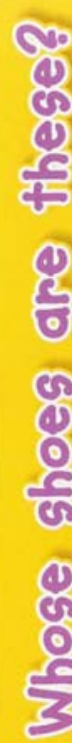
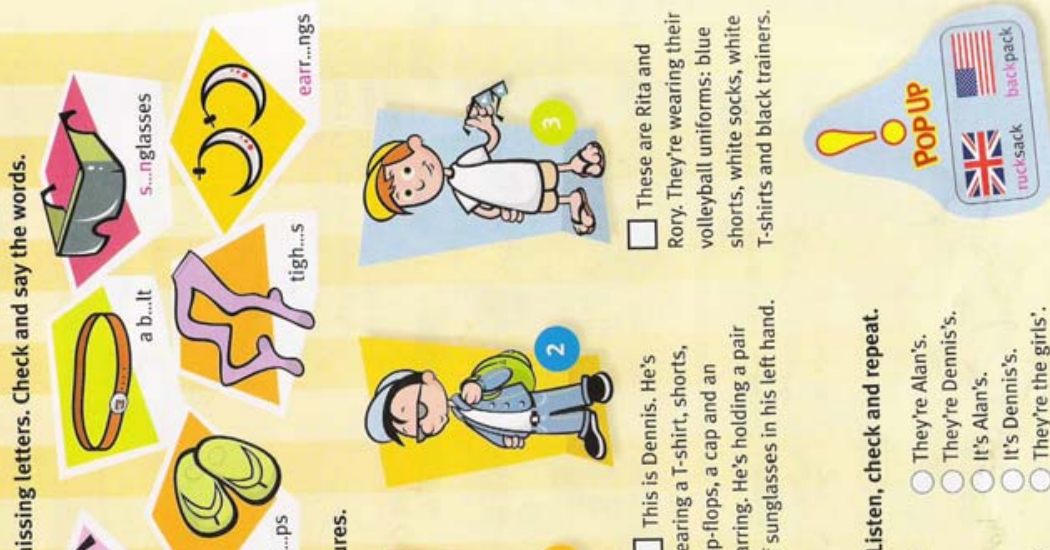

है

(1) 芒

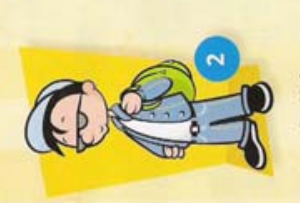

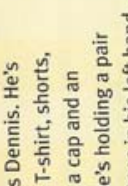

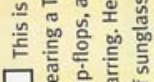

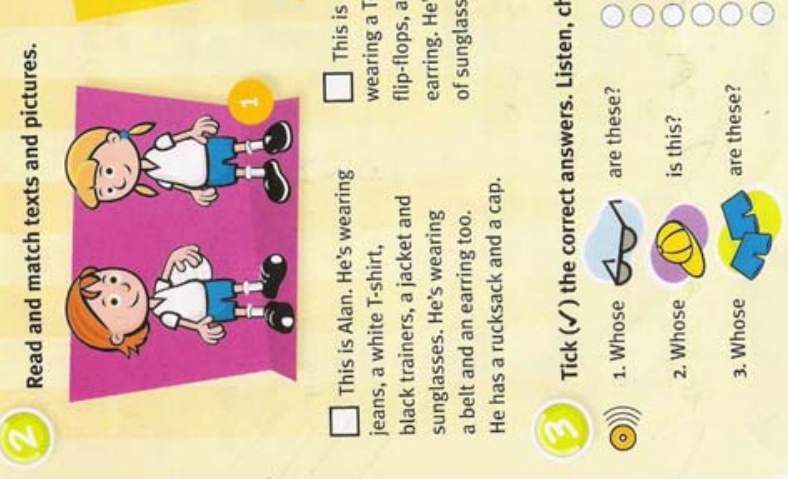




\section{A AUTORA}

Cristina Helena Evelyn Tinoco Teixeira é Mestranda no Programa de Pós-Graduação em Estudos da Linguagem, PUC-Rio. Na sua pesquisa, desenvolve estudos da multimodalidade em material didático. É professora da Cultura Inglesa. E-mail: nina.evelyn@gmail.com. 